\title{
EL IMPACTO DE LA NARRATIVA EN LA EXPERIENCIA DE LA ENFERMEDAD*
}

\section{The Impact of the Narrative on the Experience of the Disease}

\author{
Rocío Méndez del Portal \\ Universidad Femenina del Sagrado Corazón, Perú \\ https://:orcid.org/0000-0002-8864-610X \\ mariamendezd@unife.edu.pe
}

\begin{abstract}
RESUMEN
El presente artículo busca reflexionar sobre el impacto de la narrativa en la experiencia de la enfermedad. Tiene como objetivo analizar si la narrativa puede ser una herramienta para profundizar sobre esa experiencia, puesto que el hecho de narrar la propia historia implica mirarse y autocomprenderse. El trabajo inicia vinculando la narrativa con las perspectivas de primera, segunda y tercera persona, en el contexto de la enfermedad. Posteriormente, se analiza la relación entre narrativa y enfermedad, y cómo este vínculo puede favorecer la comprensión de esta última creando un discurso común. Asimismo, se evalúa el papel que juega el relato autobiográfico como posibilidad de diálogo entre autor y lector. Finalmente, se reflexiona sobre la empatía como respuesta al encuentro entre subjetividades y sus implicancias.
\end{abstract}

\section{Palabras clave:}

Narrativa, enfermedad, empatía, perspectivas de primera, segunda y tercera persona.

\begin{abstract}
This article seeks to reflect on the impact of the narrative on the experience of illness. This paper aims to analyze if the narrative can be a tool to better understand that experience, because the fact of telling one's own story implies looking at and understanding oneself.. The article begins by linking the narrative with the first, second and third person perspectives in the context of the illness. I then analyze the relationship between narrative and illness, and how this link can favor the understanding of illness by creating a common discourse. After that, I evaluate the role played by the autobiographical story as a possibility of dialogue between author and reader. Finally, I reflect on empathy as a response to the encounter between subjectivities and its implications.
\end{abstract}

\section{Keywords:}

Narrative; illness; empathy; first, second and third person perspectives.

* Esta publicación fue posible gracias a un subsidio de la John Templeton Foundation. Las opiniones expresadas en esta publicación son de la autora y no necesariamente reflejan las de la John Templeton Foundation. This publication was made possible through the support of a grant from the John Templeton Foundation. The opinions expressed in this publication are those of the autor(s) and do not necessarily reflect the views of the John Templeton Foundation. 


\section{INTRODUCCIÓN}

La crisis sanitaria que estamos viviendo y que se presentó de manera inesperada, nos permite mirarnos de manera personal, pero también como sociedad. Puede ser una oportunidad para tomar conciencia de nuestros propios límites, de nuestras relaciones con los demás y con nuestro entorno. En esta situación tan compleja y dolorosa hemos podido observar ambas caras de la moneda. Por un lado, empatía, solidaridad y cuidado; y por otro, individualismo, egoísmo e indiferencia. ¿Es posible que la narrativa contribuya a mirar al otro de manera más empática?

En el presente trabajo se reflexionará sobre cómo las perspectivas de primera, segunda y tercera persona pueden vincularse con la experiencia de la enfermedad y contribuir a establecer un diálogo entre la dicotomía subjetivo objetivo. Cabe mencionar que el recurso a estas 'perspectivas', empleado por la filosofía de la mente y de las ciencias cognitivas en las últimas décadas, proviene de la narrativa, y es utilizado para indicar el lugar desde donde una persona se aproxima a la realidad. El objetivo de este artículo es analizar si la narrativa de la enfermedad permite una mejor comprensión sobre una experiencia dolorosa y hacerle frente. En este sentido, se busca relacionar la narrativa con la empatía y su impacto en la vida social. Es decir, se pretende reflexionar sobre cómo el hecho de narrar una experiencia sobre la enfermedad puede contribuir a que el autor la comprenda mejor; pero además se busca analizar si es que ese testimonio hace posible que se establezca un diálogo con el lector que le permita entender mejor una vivencia que no es experimentada por él, pero que puede conocer e interpretar.

\section{Perspectivas de primera, segunda y tercera persona}

La persona es irrepetible e incomunicable (Crosby, 1996). El autor emplea el término 'incomunicable' para explicar que cada persona es única y no comparte su ser con otro. La incomunicabilidad se desprende de la individualidad personal, y es lo que distingue a una persona de otra. La llamada perspectiva de primera persona se apoya en esta individualidad. Sin embargo, es posible que la interioridad personal sea comunicada, es decir, una persona puede explicar, a través del lenguaje, una experiencia privada y única. Por ejemplo, cada persona experimenta esta pandemia de una manera particular, pero es posible comunicar esta vivencia a los demás.

Asimismo, Spaemann sostiene que "cada uno tiene acceso privilegiado a su propia interioridad" (Spaemann, 2010, p. 178). Contextualizando esta afirmación en el ámbito de la enfermedad, se puede señalar que, si alguien siente dolor, solo la persona que lo experimenta puede manifestarse sobre ese sentir, porque la vivencia es individual, o al menos podrá hacerlo de un modo en que otros no podrían. La experiencia propia no es idéntica a la de los demás y la manera en la que una persona experimenta el dolor es única. Pero como se mencionó líneas arriba, la perspectiva de primera persona es en otro sentido comunicable; por consiguiente, es posible describir una vivencia y dialogar con otros sobre ese sentir.

Por otro lado, la mirada científica o perspectiva de tercera persona busca objetividad. Por ejemplo, el médico que observa el estado del organismo de un paciente desde una perspectiva científica 
que apunta a los procesos biológicos, utiliza la abstracción y universalización. Pero, además, se puede señalar que es posible establecer un puente común entre el médico y el paciente. Este puente al que se hace referencia es lo que se denomina perspectiva de segunda persona, en el sentido de que el médico, al comprender la narrativa del paciente, entiende que se trata de otra subjetividad y no solo de un cuerpo objetivo que hay que curar Entonces, a través del diálogo se puede otorgar un significado compartido a la enfermedad. De acuerdo a lo señalado, la perspectiva de segunda persona puede ser entendida como una relación interpersonal, en donde hay una narrativa e interpretación de ambas partes.

Como puede notarse, sería problemático quedarnos con una sola perspectiva; el ejemplo mencionado pone de manifiesto su irreductibilidad.

\section{La narrativa como medio para entender la experiencia de la enfermedad}

Como se mencionó anteriormente, es posible vincular las perspectivas de primera, segunda y tercera persona con la narrativa. En este apartado se analizará la posible relación entre los términos 'narrativa' y 'vida' para luego llevar la reflexión hacia la experiencia de la enfermedad.

Uno de los teóricos contemporáneos más importantes de la narratividad es Paul Ricoeur, quien retoma el concepto de "construcción de la trama" planteado en la Poética de Aristóteles. Ricoeur explica que el término empleado en griego para designar la trama (mythos) puede ser entendido al mismo tiempo como fábula y como trama. Como fábula, para hablar de una historia imaginaria, y como trama, para hacer referencia a una historia bien construida. La construcción de la trama, entendida en este segundo aspecto, se refiere a la síntesis de múltiples sucesos, a la historia completa y también a la organización de elementos heterogéneos. Es decir, Ricoeur sostiene que la historia narrada es más que una enumeración de acontecimientos, puesto que está organizada de manera inteligible. En este sentido, la trama como organización de elementos heterogéneos se entiende como una concordancia discordante, en la que tiene primacía la concordancia. Además de lo señalado anteriormente, Ricoeur afirma que la construcción de la trama puede entenderse también desde un punto de vista temporal (Ricoeur, 2006, pp. 10-11). Es decir, lo que es narrado, sucede en el tiempo y lo que se desarrolla en el tiempo puede narrarse (Ricoeur, 2000, p. 190).

De esta manera la historia como síntesis de lo heterogéneo, explica Ricoeur, puede ser vista desde tres perspectivas: "la mediación entre los sucesos múltiples y la historia singular ejercida por la trama; la primacía de la concordancia sobre la discordancia; y, finalmente, la lucha entre sucesión y configuración" (Ricoeur, 2006, p. 12).

Si se retoma el punto de inicio del presente apartado -ien qué medida es posible vincular la narrativa a la vida?- Ricoeur afirma que el proceso de composición y configuración no termina en el texto mismo, sino en el acto de leer (Ricoeur, 2006, p. 15). Por ello es posible afirmar que la narrativa permite transfigurar la experiencia del lector. Es decir, el sentido de un relato surge a partir del encuentro entre el mundo del lector y el mundo del texto.

Sin embargo, cel texto no tiene límites que se encuentran dentro de la 
obra misma? Frente a la objeción de que el texto implica un límite del cual no se debería salir, Ricoeur diferencia la perspectiva hermenéutica de la perspectiva lingüística; y sostiene que la hermenéutica comienza donde la lingüística se detiene. Una obra literaria implica tres dimensiones: referencialidad, comunicabilidad y comprensión de sí. La hermenéutica, es decir, el significado de la interpretación del texto, puede ser entendida como una mediación entre el hombre y el mundo (referencialidad), entre el hombre y el hombre (comunicabilidad) y entre el hombre y sí mismo (comprensión de sí). De esta manera, Ricoeur afirma que a través de la lectura se puede vincular narrativa y vida, en el sentido de que la lectura es una forma de vivir a través de las historias narradas (Ricoeur, 2006, pp. 16-17).

Ahora bien, chasta qué punto es posible que el lector entre en diálogo con el autor de un relato de la enfermedad? ¿Cuál es el impacto de esta narrativa en el mismo autor? Arthur Frank explica que la narrativa de la enfermedad es un medio significativo para comprender la enfermedad y sus implicancias (Frank, 1993). El autor califica la narrativa de la enfermedad como una "epifanía", es decir, como momentos privilegiados en los que es posible realizar un cambio en la vida. Además, señala que de alguna manera la epifanía puede ser entendida como una especie de "renacimiento"; este cambio es posible a través de la narración de la propia experiencia. De esta manera, podemos narrar en quién nos hemos convertido luego de la enfermedad (nueva identidad) y así queda disponible para quienes están afrontando una situación similar o no (Frank, 1993, p. 42).

Entonces, ¿cuál es el papel de la narrativa para comprender la experiencia de la enfermedad de otra persona? Frank señala que es posible considerar a una persona enferma como narradora de historias (Frank, 1998), no solamente en el sentido de que esas historias son narradas por el enfermo para una mejor comprensión de su propia experiencia, sino también para el personal de la salud, porque una historia requiere de alguien que la escuche. En una relación médico-paciente se puede hablar de un 'nosotros', en el sentido de que compartir una historia permite generar relaciones mutuas. El autor afirma que cuando una persona enferma cuenta su historia revela el significado que ha construido alrededor de su enfermedad. Al ser escuchada se genera una reciprocidad entre dos personas (médico y paciente) que se encuentran y tienen un conocimiento mutuo.

A este encuentro entre subjetividades también hace referencia Havi Carel en el artículo "Phenomenology and its application in medicine" (2011), donde utiliza la fenomenología como método filosófico para describir la experiencia de la enfermedad haciendo énfasis en el relato en primera persona. Siguiendo a Merleau-Ponty, Carel distingue el cuerpo como objeto y como sujeto. Como objeto se refiere al cuerpo físico, materia de estudio de la medicina; y como sujeto, al cuerpo vivido, es decir, a la experiencia vivida en primera persona. La autora menciona que cuando una persona experimenta una enfermedad, ésta impacta en todas las dimensiones de su vida, no solo en la parte física, donde se concentra a menudo la perspectiva científica en tercera persona. Para Carel estas dos perspectivas -la del paciente (primera persona) y la del médico (tercera persona)- deben armonizarse. Así, a través del diálogo médico-paciente estas diferentes perspectivas de la enfermedad 
permiten elaborar una comprensión conjunta de la misma.

Hasta este punto se puede afirmar que la narrativa de la enfermedad permite al autor comunicar el significado que ha elaborado sobre su propia experiencia, además de establecer un diálogo entre el narrador y el lector. Si se lleva este aspecto a la relación médico-paciente, se puede afirmar que este último narra su experiencia de enfermedad, que, al ser escuchada e interpretada por el médico, se hace posible la construcción de un significado compartido de la enfermedad.

\section{La empatía como encuentro}

Las experiencias no vividas en primera persona pero que han sido recibidas a través de un relato autobiográfico, ¿pueden generar empatía? ¿Qué sucede con este encuentro de subjetividades? Suzanne Keen define la empatía como el afecto compartido espontáneo o vicario que puede ser provocado al presenciar el estado emocional de otra persona, al escucharla, o incluso al leerla (Keen, 2006 , p. 208).

Por su parte, Sutton señala en relación a las narrativas del padecer que para comprenderlas hay que tener en cuenta un concepto clave, el de la experiencia, puesto que en ella está presente la corporalidad, la identidad, la memoria, la propia trayectoria de vida, el pasadopresente-futuro, la pertenencia social y las relaciones intersubjetivas (Sutton, 2016, p. 61). De ahí la importancia de resaltar el aspecto hermenéutico al acercarse a una narrativa autobiográfica, puesto que abarca no solo la identidad personal del narrador y la comprensión que él tiene de sí mismo, sino también la realidad social y cultural en la que se encuentra. La escritura de un relato autobiográfico permite reconstruir la propia experiencia y vincularla con creencias, emociones, afectos, razonamientos, significados e interpretaciones que una persona hace en un contexto determinado. Al ser narrado en primera persona implica encontrar un estilo y voz propios para poder comunicar la propia interioridad, que al ser recibida puede generar identificación o comprensión de la experiencia narrada, favoreciendo la empatía.

Asimismo, a pesar de la amplia diversidad de géneros literarios en los que se ha fragmentado el acto de narrar, existe una unidad funcional entre ellos. Ricoeur afirma que esta unidad se debe al carácter temporal de la narrativa, que se da tanto en los relatos históricos o autobiográficos como en la ficción (Ricoeur, 2000).

Lindón (1999) señala que la narrativa autobiográfica no debe identificarse con la acción misma, sino que son fragmentos de una experiencia vivida y narrada por una persona que nos invita interpretarla. Que sea un relato implica que el narrador ha elaborado una estructura e hilo conductor particular de una experiencia que considera significativa socialmente. Lindón añade, siguiendo a Ricoeur, que el relato autobiográfico permite narrar las experiencias significativas socialmente gracias al lenguaje.

Uno de los rasgos que identifican a las narrativas o los relatos autobiográficos es precisamente su carácter experiencial. Se narran experiencias vividas por el narrador, recordadas, interpretadas, conectadas, en las que hay otros actores, pero siempre son experiencias de quien habla (Lindón, 1999, p. 298).

Aquí se resalta que la experiencia narrada es única, pero es posible que sea transmitida a través del lenguaje. Por otro 
lado, así como el lenguaje hace posible la narración de una experiencia, surge la pregunta por el papel de la memoria en el relato autobiográfico. La memoria permite reconstruir experiencias vividas; sin embargo, ¿hasta qué punto esta experiencia llega al lector tal y como sucedió? Incluso el mismo narrador podría tener dificultad para reconstruir el pasado tal como ocurrió, porque su misma subjetividad puede interponerse y presentar la experiencia vivida con diversos matices. Por ejemplo, la narración de una experiencia dolorosa está entrelazada con emociones, sentimientos, interpretaciones que una persona realiza desde su propia subjetividad. Incluso, al ser narrada, es posible que a esta reconstrucción se añada un factor estético. Entonces, ¿no queda distorsionada la experiencia al ser contada?

Frente a este cuestionamiento se puede afirmar que los relatos autobiográficos no tienen como objetivo demostrar la verdad, sino reconstruir una experiencia inscrita en la historia haciendo uso del lenguaje y la memoria (Lindón, 1999, p. 305). De esta manera, se produce un encuentro entre el lector y el narrador autobiográfico.

La historia que narro es la mía propia, pero los lectores pueden sumar sus vidas a la mía y cambiar lo que he escrito para que se adapte a sus propias situaciones. Tales relaciones se convierten en amistad, una amistad comenzada en la conversación (Frank, 1991, p. 3).

Este diálogo entre el autor y el lector, hace posible que el lector empatice con el autor de la narración.

Cuando una persona narra su propia experiencia, no solo invita a conocer esa vivencia a los posibles receptores de la misma, sino que también realiza un proceso que implica autoconocimiento, interpretación y reconstrucción a través de la memoria.

Sutton explica que la "narrativa del padecer" surge de la comunicación entre dos o más personas que transmiten experiencias que tienen un sentido para quienes la expresan o interpretan. El crear o escuchar una narrativa es un proceso activo y constructivo en el cual intervienen aspectos personales y culturales. Asimismo, la narrativa implica aprendizaje en cuanto a comprensión de experiencias que no se han vivido en primera persona (Sutton, 2016).

Como se ha venido señalando, la narrativa de la enfermedad implica comunicar una experiencia única. La manera como es vivida e interpretada la enfermedad responde a la interioridad de cada sujeto. Es por ello que el diálogo entre quien narra y quien recibe la narración puede entenderse como un encuentro necesario para comprender la experiencia del otro.

Si retomamos la pregunta, ¿̇la narrativa sobre la enfermedad puede generar empatía en quien la escucha o lee? La respuesta es sí, en el sentido de que el relato autobiográfico hace que el receptor de la historia se identifique con el narrador o que pueda comprender e interpretar una experiencia que no ha sido vivida por él. De esta manera se produce un diálogo que es necesario resaltar en este tiempo de pandemia. La crisis sanitaria que vivimos actualmente pone de manifiesto la imposibilidad de reducir la realidad a una sola mirada. Es necesario conectar las experiencias subjetivas y reconocer que es posible el encuentro. La experiencia empática permite la comunicación entre dos subjetividades, que si bien, como se 
ha mencionado anteriormente, pueden distinguirse, es necesario vincular.

\section{Discusión final y conclusiones}

Según la reflexión realizada, se puede afirmar que, aun dentro de ciertos límites, la narrativa autobiográfica permite comunicar la propia experiencia mediante el lenguaje y crear un escenario en donde es posible que una persona que está experimentando una enfermedad pueda mirarse, entenderse, interpretarse y reconstruirse; y que al mismo tiempo entre en diálogo con el lector o interlocutor de la narración. Este encuentro permite, además, que el lector de la narración acceda, conozca e interprete una experiencia que no ha sido vivida por él, y genere empatía con el autor.

La narrativa es un medio adecuado no solo para generar comprensión, también puede serlo para movilizar a la acción. En este sentido, Ricoeur, citado por Zapata, señala:

Ninguna narración es 'éticamente neutra'. Es precisamente por la narración que 'la literatura llega a ser un vasto laboratorio en el que son ensayadas estimaciones, evaluaciones, juicios de aprobación y de condenación por los que la misma narratividad sirve de propedéutica a la ética' (Zapata, 2008, p.135).

\section{REFERENCIAS BIBLIOGRÁFICAS}

Beltran, P. (2016). Leer narraciones, fundamento de la empatía. Medicina Narrativa, 6(1).

Carel, H. (2011). Phenomenology and its application in medicine. Theoretical Medicine and Bioethics, 32 (1), 33-46.
Carel, H. (2016). Phenomenology of illness. Oxford University Press.

Crosby, J. 1996.The Selfhood of the Human Person. Washington DC: The Catholic University of America Press.

Frank, A. W., E Liberti, S. (1991). Volver a vivir. Selector.

Frank, A (1993). The Rhetoric of Self-Change: Illness Experience as Narrative. The Sociological Quarterly, 34 (1), 39-52.

Frank, A. (1998). Just listening: narrative and deep illness. Families, Systems, E Health, 16(3), 197-212.

Frank, A. (2002). Why Study People's Stories? The Dialogical Ethics of Narrative Analysis. International Journal of Qualitative Methods, 109. 117.

Keen, S. (2006). A Theory of Narrative Empathy. Narrative, 14(3), 207-236.

Lindón, A. (1999). Narrativas autobiográficas, memoria y mitos: una aproximación a la acción social. Economía, sociedad y territorio, 2(6), 295-310.

Ricoeur, P. (2000). Narratividad, fenomenología y hermenéutica. Anàlisi: quaderns de comunicació $i$ cultura, 189-207.

Ricoeur, P. (2006). La vida: un relato en busca de narrador, Ágora: Papeles de Filosofía, 25(2), 9-22.

Spaemann, R. 2010 [1996]. Personas. Acerca de la distinción entre 'algo' y 'alguien'. Pamplona: EUNSA. 
Sutton, L. H. (2016). ¿Cómo analizar las narrativas del padecer?: construcción de una propuesta teórico metodológica. Revista CONAMED, 21(2), 60-65.

Zapata, G. (2008). Ética narrativa en Paul Ricoeur. Universitas Philosophica, (50), $121-140$.

Fecha de recepción: 10/05/2021

Fecha de aceptación: 18/05/2021 